\title{
Utility of Sulfobutyl Ether $\beta$-Cyclodextrin Inclusion Complexes in Drug Delivery: A Review
}

\author{
O. DAS, V. M. GHATE AND S. A. LEWIS*
}

Department of Pharmaceutics, Manipal College of Pharmaceutical Sciences, Manipal Academy of Higher Education, Manipal-576 104, Karnataka, India

Das et al.: Review on sulfobutyl ether $\beta$-cyclodextrin complexes

\begin{abstract}
The potential of $\beta$-cyclodextrins as a pharmaceutical aid has been established through several decades of research. However, some $\beta$-cyclodextrins are reported to be toxic causing deleterious effects on long term usage. In the recent past, sulfobutyl ether $\beta$-cyclodextrin, a modified $\beta$-cyclodextrin has captured interest as a comparatively safer and effective $\beta$-cyclodextrin for increasing the solubility and the bioavailability of biopharmaceutical classification system class II drugs. Sulfobutyl ether $\beta$-cyclodextrin has demonstrated immense potential in addressing solubility and stability issues associated with formulation of drugs. Till date no comprehensive report on their utility in drug development has been published. Hence, this review focusses on the structure, properties, preparation techniques and applications of sulfobutyl ether $\beta$-cyclodextrin inclusion complexes. Investigation of the feasibility of forming stable inclusion complexes of sulfobutyl ether $\beta$-cyclodextrin and various drugs as guest molecules using molecular modelling techniques have been elaborated in the review. Incorporation of sulfobutyl ether $\beta$-cyclodextrin complexes into novel drug delivery systems (liposomes and nanoformulations) have been summarized along with various methods of preparation and the clinical safety. Molecular modelling approach discussed in this review, coupled with wet-lab validation of the complexes, will enable a faster transit of the delivery systems into the clinical setting.
\end{abstract}

Key words: Sulfobutyl ether $\beta$-cyclodextrin, inclusion complexes, drug delivery, modelling, solubility, stability

Cyclodextrins (CDs) belong to the family of cyclic oligosaccharides. It consists of 6 to 8 glucose units linked by 1,4-glucosidic bonds. The structure of the $\mathrm{CD}$ presents an internal hydrophobic cavity, which facilitates the inclusion of the various guest molecules within them ${ }^{[1]}$. On the basis of structure they are basically of three types namely $\alpha, \beta$ and $\gamma$-CDs comprising of 6,7 and 8 glucopyranose units, respectively. Till date parent $\mathrm{CD}$ and their various derivatives have found a wide range of applications in food, pharma and chemical industry. They are of great utility in the field of drug delivery and play a great role in formulation development due to their influence on solubilility, dissolution rate, chemical stability, and absorption properties of drug candidates. The continued interest in $\mathrm{CD}$ as functional excipients can be attributed to their ring structure and ability to entrap guest molecule within their internal cavity.

Sulfobutyl ether $\beta$-CDs (SBE- $\beta-C D)$ are classified under the class of modified $\beta$-CDs. These modified CDs confer added benefits to the formulation and thus are of interest than the parent CDs to a pharmaceutical

*Address for correspondence E-mail: s.lewis@manipal.edu

July-August 2019 scientist. The parent CDs have been reported to have drawbacks such as, low water solubility, tendency to induce haemolysis and in vivo cytotoxicity as they bind to mucous membrane and extract the cholesterol, which disrupts the bi-lipid structure of the cell membrane ultimately leading to haemolysis ${ }^{[2,3]}$. Even though these are widely explored, the parent CDs have limited options for flexibility on routes of administration other than non-parenteral routes due to reports on causing renal damage upon parenteral administration. This nephrotoxicity is caused due to increased lysosomal activity and necrosis of the cells ${ }^{[1]}$. $\beta-C D$ has a limited aqueous solubility and hence the precipitation of drugs is seen on standing for a long time ${ }^{[4]}$. Also they have several shortcomings related to size, shape and stability ${ }^{[3]}$.

This is an open access article distributed under the terms of the Creative Commons Attribution-NonCommercial-ShareAlike 3.0 License, which allows others to remix, tweak, and build upon the work non-commercially, as long as the author is credited and the new creations are licensed under the identical terms

Accepted 07 May 2019

Revised 27 December 2018

Received 21 August 2018

Indian J Pharm Sci 2019;81(4):589-600 
The aforementioned limitations of natural CD have been overcome by attaching a sulfobutyl group to the parent molecule forming SBE- $\beta-C D$. This derivative of $\mathrm{CD}$ has several advantages over parent $\mathrm{CD}$ that include increased water solubility, improved binding capacity of the drugs for complexation, and low toxicity profile ${ }^{[3,5]}$. The SBE- $\beta-C D$ exhibit significantly higher hemocompatibility when compared to the parent $\beta$-CD. When the hydroxyl groups of glucopyranose units are substituted with anionic groups such as sulfate and sulfobutyl-ether the CD showed negligible haemolytic activity due to its lower ability to derange and solubilize membrane lipids ${ }^{[6]}$. In vivo studies have shown that SBE- $\beta$-CDs were pharmacologically inactive and well tolerated at high doses. In a study it was found that SBE- $\beta$-CDs administered intravenously were filtered renally and eliminated intact in urine as inulin clearly suggesting that these have little or no nephrotoxicity ${ }^{[4,6]}$. The SBE $\beta$-CDs have also shown antiangiogenic property when co-administered with angiostatic steroids ${ }^{[6]}$.

\section{Structure:}

SBE- $\beta$-CDs are homogeneous, non-hygroscopic and crystalline substances that belong to the class of cyclic oligosaccharides. SBE- $\beta-C D$ or $\mathrm{SBE}_{7}-\beta-\mathrm{CD}$ has seven $\alpha$-D glycopyranose units attached in a manner, which forms a torus ring-like structure ${ }^{[1]}$. SBE- $\beta$-CDs are prepared by substituting the primary or secondary hydrogen of the hydroxyl groups of $\beta-C D$ with sulfobutyl groups. In SBE- $\beta-C D$, the average degree of substitution (DS) is 6.8 and hence it has about 7 negative charges associated with it. These negative charges are counterbalanced by adding sodium ions ${ }^{[7]}$ as shown in the fig. 1 .

\section{Molecular modelling:}

With the advancement in the molecular modelling and computational techniques, the interaction of the SBE$\beta-C D$ and the guest molecules can be easily visualised and explained. The software's such as GOLD ${ }^{\circledR}$ provided under the Cambridge Structural Database suites and Maestro ${ }^{\circledR}$ provided by the Schrodinger Inc., are widely used for these purposes. The software is able to explain the binding affinity and the most stable conformation based on certain scoring mechanisms and the determination of possible interactions and formation of bonds between the various functional groups of the SBE- $\beta-C D$ and the complexed molecules ${ }^{[8]}$. The ring-like structure of SBE- $\beta-\mathrm{CD}$, when viewed in $3 \mathrm{D}$, (fig. 2) is basically barrel-shaped or more precisely

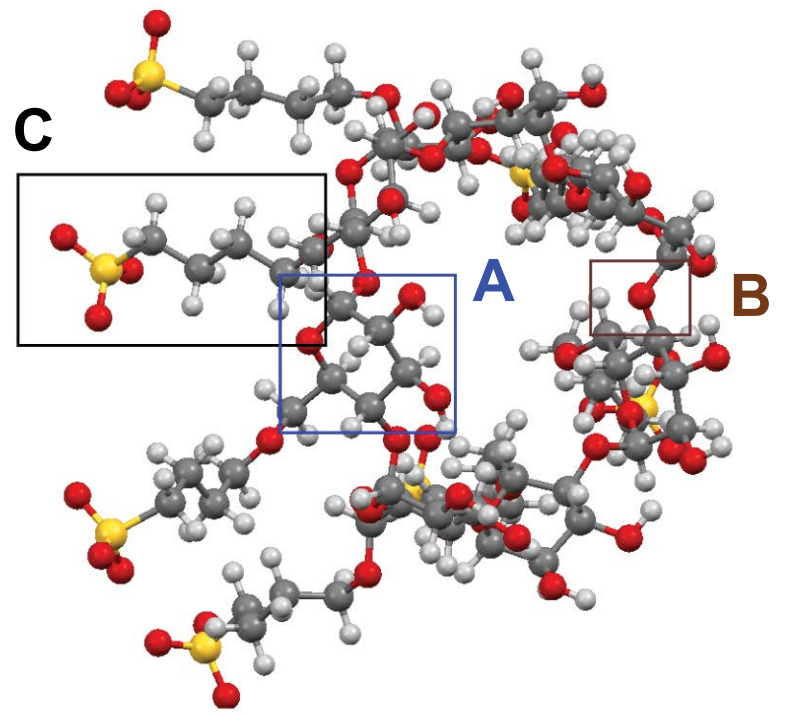

Fig. 1: 3D-moleculer Structure of SBE- $\beta$-CD

(A) Glucopyranose unit, (B) ether linkages, and (C) sulfobutyl groups modelled using the Mercury ${ }^{\circledR}$ module of the Cambridge suites. Oxygen atoms are colored red, sulphur atoms are yellow and hydrogen atoms are white

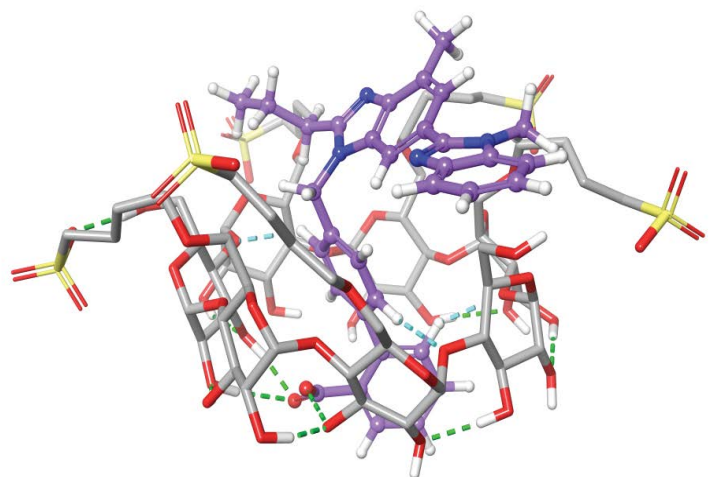

Fig. 2: Inclusion complex of SBE- $\beta-C D$ and telmisartan Inclusion complex was modelled using the Maestro ${ }^{\circledR}$ module of the Schrodinger suites ${ }^{[8]}$. The drug can be clearly seen to be fitted well within the hydrophobic cavity of SBE- $\beta-C D$ with numerous hydrogen bonds between the host and the guest molecule

looks like a conical cylinder with openings at two ends with two different diameters. Therefore, if all the primary hydroxyl groups are present at the top portion, then all the secondary hydroxyl groups are located at the bottom portion ${ }^{[1]}$. In these molecules, the inner circumference or the cavity is lined by hydrogen atoms or glycosidic oxygen bridges and hence has low polarity that favours the attachment of lipophilic molecules while the hydroxyl groups present on the outer surface makes them hydrophilic and increases solubility. To customise the chemical properties of the molecule, the hydroxyl groups can be substituted using other functional groups such as sulfobutyl ether or hydroxyl propyl ${ }^{[5]}$. 
SBE- $\beta-C D$ is a negatively charged molecule due to the sulfobutyl group present in it. The charged sulfonate groups of sulfobutyl ether moieties have two parts, one being a hydrophobic tail that is attached to the cyclodextrin cavity, which accounts for the hydrophobicity of the interior cavity and the other the charged head group. Therefore, introducing a charged group in the cavity reduces its complexing ability. Interactions of SBE- $\beta-C D$ with various anionic, cationic and neutral molecules were studied by Zia et al. ${ }^{[7]}$, who reported that neutral molecules have greater binding capacity as compared to anionic and cationic molecules. Positively charged substrate did not show considerable change in the binding strength as compared to neutral molecules. Whereas the negatively charged substrate decreased the binding capacity 40 times, which was due to ion repulsion effect.

For the formation of the inclusion complex the principle force that comes into play is the hydrophobic effect. The other forces that contribute to the stability of complex are dispersive interaction and hydrogen bonding by hydroxyl groups of SBE- $\beta$-CD. The nonpolar molecule that has suitable size occupies the inner cavity of the SBE- $\beta-C D$, which was initially occupied by water molecules with high energy. As the drug molecule occupies this cavity, water molecules move into the bulk solution, forming a stable drug and carrier complex. The SBE- $\beta-\mathrm{CD}$ molecules act as a protective shell. Once this stable complex is administered, it reaches the blood stream and then dissociates to release the original drug, which diffuses to the site of action and the SBE- $\beta-C D$ shell is eliminated ${ }^{[9]}$.

\section{PHYSICOCHEMICAL PROPERTIES AND DS}

The physicochemical properties of SBE- $\beta-C D$ are represented in Table 1. DS is the average number of substituents that have reacted with one CD molecule. In other words, DS represented the number of hydroxyl groups that have been substituted in each molecule. The physicochemical properties as well as complexation capacity of SBE- $\beta-C D$ is influenced by the DS. Though many derivatives of SBE- $\beta-C D$ with various $D S$ have been reported, the $\mathrm{SBE}_{7}-\beta-\mathrm{CD}, \mathrm{SBE}_{4}-\beta-\mathrm{CD}$ and $\mathrm{SBE}_{1}-$ $\beta$-CD (with DS 7, 4 and 1, respectively) are extensively used in pharmaceutical formulations.

Thompson et al. ${ }^{[10]}$ carried out a comparative study of the haemolytic activity of all the derivatives of SBE$\beta-C D$ at concentrations typically used to solubilize
TABLE 1: PHYSICOCHEMICAL PARAMETERS OF SBE- $\beta-C D$

\begin{tabular}{lc}
\hline Parameter & Value \\
\hline $\begin{array}{l}\text { Crystal structure } \\
\text { Colour }\end{array}$ & $\begin{array}{c}\text { Amorphous } \\
\text { White }\end{array}$ \\
$\begin{array}{l}\text { Acceptability in water } \\
\text { substitution according to } \\
\text { pharmacopoeia } \\
\text { Charge }\end{array}$ & More than $1200 \mathrm{mg} / \mathrm{ml}$ \\
& $6.2-6.9$ \\
$\begin{array}{l}\text { Suitability for taste } \\
\text { masking }\end{array}$ & $\begin{array}{c}\text { Polyanionic (Na salt) } \\
\text { Native SBE-B-CDs are not } \\
\text { suitable due to salty taste. }\end{array}$ \\
& $\begin{array}{c}\text { The sodium salt of SBE-B-CDs } \\
\text { (Captisol } \circledast \text { ) is tasteless and can } \\
\text { be used in oral formulations } \\
\text { for taste masking }\end{array}$ \\
\hline
\end{tabular}

the pharmaceutical formulations. It was found that haemolytic activity was in the order, $\mathrm{SBE}_{7}-\beta-\mathrm{CDs}<$ $\mathrm{SBE}_{4}-\beta-\mathrm{CDs}<<\mathrm{SBE}_{1}-\beta-\mathrm{CDs}<<\beta-\mathrm{CDs}$. These results showed that $\mathrm{SBE}_{7}-\beta-\mathrm{CDs}$ had the least haemolytic activity and are the safest for use as a pharmaceutical excipient $^{[11]}$. In a comparative study done by Zia et al. to study the effect of DS and alkyl chain length on complexation using various steroids (progesterone, testosterone, digoxin and phenytoin), it was found that progesterone showed minimum influence whereas digoxin and phenytoin showed a descending correlation (when DS versus binding constant $\mathrm{K}$ was plotted) the one with lowest DS had the strongest binding. Testosterone on the other hand showed an ascending correlation $^{[4]}$. Zia et al. ${ }^{[11]}$ correlated the DS of SBE$\beta-C D$ and the binding constants of molecules and concluded that there was no uniform trend observed, but when enthalpy and entropy were considered a distinct pattern was observed. It was reported that as the number of SBE groups were increased the complexation of the substrates to SBE- $\beta$-CD were more entropy favoured. de Boer et al. ${ }^{[12]}$ summarised the effect of DS on the applicability of different derivatives of $\mathrm{CD}$ in capillary electrophoresis for chiral separations in pharmaceutical analysis. He emphasized that the use of commercially available CDs having a defined DS may lead to a better modelling, optimization, reproducibility, and to a more rugged separation system ${ }^{[12,13]}$.

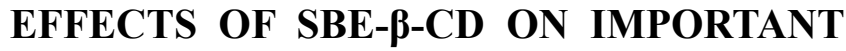 DRUG PROPERTIES}

\section{Solubility and dissolution:}

SBE- $\beta$-CD has been reported as one of the best solubility enhancers. It has been extensively used for formulation of drugs with poor water solubility (Table 2). It formed 
dynamic, non-covalent, water soluble inclusion complexes. SBE- $\beta$-CD acted as a hydrophilic carrier for drugs having inadequate molecular characteristics for complexation and hence improving aqueous solubility of the drugs and dissolution rate ${ }^{[14]}$. Also another suggested mechanism for improving dissolution rate and solubility is that upon complexation with SBE- $\beta$ $\mathrm{CD}$ reduction of crystallinity or amorphization took place ${ }^{[15-20]}$. The factors that affect the solubility also affect rate of dissolution. Dissolution rate is directly proportional to solubility. It is so because higher the solubility of drug, higher will be the concentration of drug in the dissolution medium and hence a high dissolution rate ${ }^{[21-35]}$. Solubilizing effect of SBE- $\beta-C D$ on 22 poorly water drugs were compared to $\beta-C D$ and DM-CD [heptakis-(2,6-di-O-methyl)- $\beta$-CD]. SBE- $\beta$ $\mathrm{CD}$ was found to be more effective than $\beta-\mathrm{CD}$ but less than $\mathrm{DMCD}^{[14]}$. SBE- $\beta-C D$ was also reported to be a promising solubilising agent for essential oils and their components ${ }^{[36]}$.

\section{Permeability:}

SBE- $\beta$-CD has also been used as a membrane permeability enhancer. Drugs that have poor water solubility cannot permeate through biological membranes. SBE- $\beta-C D$ formed inclusion complex and this acted as a carrier for the drug. The complex carries the drug through the aqueous barrier in the

\begin{tabular}{|c|c|c|}
\hline Drug & Therapeutic use & Reference \\
\hline Carbamazepine & Anticonvulsant & 15 \\
\hline Curcumin & $\begin{array}{c}\text { Antiinflammatory, } \\
\text { anticancer }\end{array}$ & 16 \\
\hline Vinpocetine & $\begin{array}{c}\text { Antiaging, memory } \\
\text { enhancer }\end{array}$ & 17 \\
\hline Zalpelon & Sedative, hypnotic & 18 \\
\hline Thalidomide & Antileprotic, anticancer & 19 \\
\hline Econazole nitrate & Antifungal & 20 \\
\hline Honokoil & $\begin{array}{c}\text { Anticancer, } \\
\text { antiinflammatory }\end{array}$ & 21 \\
\hline Astaxanthine & Antioxidant & 22 \\
\hline Erlotinib & Anticancer & 23 \\
\hline Pilocarpine & Cholinergic agonist, & \\
\hline Phenytoin & miotic & 24 \\
\hline Nateglinide & Anticonvulsant & 25 \\
\hline Olmesartan & Antidiabetic & 26 \\
\hline medoxomil & Antihypertensive & 27 \\
\hline Lacidipine & Antihypertensive & 28 \\
\hline Spiranolactone & Antihypertensive & 30 \\
\hline DY-9760e & Cytoprotective agent & 31 \\
\hline Danazole & Steroid & 32 \\
\hline Ziprasidone mesylate & Antipsychotic & 33 \\
\hline Mephalan & Anticancer & 34 \\
\hline Carmustine & Anticancer & 34 \\
\hline Midazolam & Antianxiety, sedative & 35 \\
\hline
\end{tabular}

biological membranes ${ }^{[14]}$. When SBE- $\beta-C D$ is given as an oral formulation, upon reaching the gastrointestinal mucosa, dissociation of the complex takes place and the free drug is released. This free CD has limited absorption in the gastrointestinal tract; it interacts with the gastrointestinal mucosa and reversibly increases the permeability ${ }^{[18]}$. Inclusion complex of sevoflurane has shown significantly higher blood brain barrier permeability ${ }^{[37]}$. Inclusion complexes of erlotinib and zaleplon have also shown increased permeability due to increase in aqueous solubility ${ }^{[18,23]}$.

\section{Bioavailability:}

SBE- $\beta$-CD enhanced the bioavailability of insoluble or sparingly soluble drugs by improving its solubility, dissolution as well as permeability. Drugs which are hydrophobic in nature show poor bioavailability, SBE- $\beta$-CD forms inclusion complex, enhances the hydrophilicity and makes the drug more permeable across the biological membranes; hence these drugs are available to a greater extent in the body. Solid inclusion complex of phenytoin showed a 1.6 fold increase in peak plasma concentration and 2 fold increase in bioavailability when compared to the plain drug $^{[25]}$. Inhalational anaesthetic sevoflurane has high lipophilicity and poor aqueous solubility, thus cannot be given orally or intravenously to a patient. An inclusion complex of SBE- $\beta$-CD with sevoflurane was developed and on evaluation there was an improvement in the bioavailability and blood brain barrier permeability ${ }^{[37]}$. Erlotinib and SBE- $\beta-C D$ complex showed a 3.6 fold increase in oral bioavailability leading to reduced dose and dose related side effects ${ }^{[23]}$. Inclusion complexes of olmesartan medoxomil and lacidipine with SBE- $\beta$ $\mathrm{CD}$ showed a significantly high bioavailability, AUC and $\mathrm{C}_{\max }$ than plain drug suspension due to enhanced solubility ${ }^{[27,28]}$. The bioavailability of amiodarone HCL in fasted state was improved by complexation with SBE- $\beta-C D$. It was reported that the inclusion complex has been able to minimise the food effect on bioavailability ${ }^{[29]}$. SBE- $\beta-C D$ was also used to prepare intramuscular formulation of posoconazole. The bioavailability of posoconazole was markedly improved by complexation with SBE- $\beta-\mathrm{CD}^{[38]}$.

\section{Stability:}

SBE- $\beta$-CDs have been reported to enhance stability of many drugs compared to other $\mathrm{CDs}^{[14]}$. Drugs are prone to various kinds of degradation such as hydrolysis, photodecomposition, oxidation and enzymatic degradation. CDs form inclusion complex, 
by providing a cavity where the drug molecule gets entrapped and stay protected from solvents or enzymes that cause degradation. They act as a molecular shield, encapsulating the labile drug at molecular level and hence the degradation is at a slower rate than the free drugs. Thalidomide complex with SBE- $\beta-C D$ showed more stability than the parent drug in alkaline condition $^{[19]}$. SBE- $\beta-C D$ increased the aqueous stability of pilocarpine at $\mathrm{pH} 7$ and also increased the ocular absorption. SBE- $\beta-C D$ was well tolerated and did not affect the miotic response when administered with the drug $^{[25]}$. SBE- $\beta-C D$ increased the stability constants of nateglinide and honkoil ${ }^{[21,26]}$. SBE- $\beta-C D$ increased the photostability of the DY-9760 $\mathrm{e}^{[31]}$. SBE- $\beta-C D$ was reported to have shown better stability against hydrolysis as compared to HP- $\beta-\mathrm{CD}$ for melphalan and carmustine $^{[34]}$.

\section{SBE- $\beta$-CD IN FORMULATIONS ADMINISTERED BY DIFFERENT ROUTES}

SBE- $\beta-C D$ is highly biocompatible and can be convenientely incorporated into various types of formulations to overcome limitations of the conventional formulations and can be administered parenterally, ophthalmically, orally, nasally, topicaly and via inhalation (Table 3). An average of $76 \%$ of all formulations with SBE- $\beta$-CD are under the parenteral category and the nasal, ophthalmic and oral dosage forms constitute $8 \%$ each totalling upto the rest of the market share.

\section{Oral delivery:}

SBE- $\beta-C D$ when used in drug delivery systems administered orally was found to improve the bioavailability of drugs by increasing the solubility and improving the rate and extent of dissolution ${ }^{[19]}$. It showed increased stability of drug when exposed to different $\mathrm{pH}$ conditions, and various enzyme systems present in the different areas of the gastrointestinal tract. SBE- $\beta-C D$ has been successfully used for reduction of drug-induced irritation and to modify the time of drug release.

For an inclusion complex of thalidomide prepared with SBE- $\beta-C D$ a considerable increase in aqueous solubility and aqueous alkaline stability was reported ${ }^{[19]}$. Molecular encapsulation of thalidomide when given orally due to its immediate release property showed improved drug absorption and higher distribution due to solubilisation, a significant reduction in tumor formation was observed in the experimental animals. Compared to the free drug, the enhanced efficacy of the thalidomide-SBE- $\beta-C D$ complex suggests that such a delivery system would be very useful for the treatment of cancers ${ }^{[19,39]}$. Rao et al. worked on improving the release pattern of a poorly water soluble prednisolone from a HPMC-based matrix tablet. SBE- $\beta-C D$ was used as a solubilising agent. Tablets were prepared by direct compression using a physical mixture of SBE$\beta-\mathrm{CD}$, prednisolone, and the polymer. It was observed that the drug release rate was dependent on the molar ratio of SBE- $\beta-C D$ and prednisolone and not on the amount of SBE- $\beta-C D$ present in the formulation. It could be concluded that matrix formulations containing SBE- $\beta-C D$ may be used for the complete and controlled delivery of drugs with limited aqueous solubility ${ }^{[40]}$. The sodium salt of SBE- $\beta$-CD was used

TABLE 3: EFFECT OF SBE- $\beta-C D$ ON VARIOUS DRUG DELIVERY ROUTES AND SYSTEMS

\begin{tabular}{|c|c|c|c|}
\hline Drug & Delivery system & Effect & Reference \\
\hline Thalidomide & Immediate release & Increased bioavailability & 19 \\
\hline Prednisolone & Matrix tablet & Increased solubility & 41 \\
\hline Testosterone & Osmotic pump tablet & Faster release from the tablet, increased solubility & 42 \\
\hline Prednisolone & $\begin{array}{l}\text { Controlled porosity osmotic } \\
\text { pump pellets }\end{array}$ & Improved solubility, increased drug release rate & 43 \\
\hline Spironolactone & Paediatric oral solution & Increased bioavailability, better oral absorption & 30 \\
\hline Danazol & Buccal tablet & Increased mucoadhesion and bioavailability & 45 \\
\hline Econazole nitrate & Ocular delivery & Better drug activity due to sustained activity & 20 \\
\hline Pilocarpine & Ocular delivery & Increased ocular bioavailability & 40 \\
\hline Propofol & Intra venous & Same PK and PD as of the current marketed product & 54 \\
\hline Ondansetron & Nasal delivery & Increased permeation rate & 49 \\
\hline Irinotecan & Liposomal formulation & Improved retention & 58 \\
\hline Proteins (BSA) & Pulmonary delivery & Sustained activity & 51 \\
\hline Vincristine & Liposomes & Improved drug retention & 59 \\
\hline Etomidate & Intravenous & Reduced side effects & 53 \\
\hline Pilocarpine & Eye drops & Improved tolerability, reduced irritation & 24 \\
\hline Thalidomide & Nasal powder & Improved dissolution rate & 50 \\
\hline Famotidine & Controlled release tablet & Slow release of drug & 44 \\
\hline Chlorpromazine & Osmotic pump tablet & $\mathrm{pH}$ dependent release profile & 60 \\
\hline
\end{tabular}


as a solubilizing agent and as an osmotic agent in a controlled porosity osmotic pump system for release of a poorly water soluble compound, testosterone. The release was compared with hydroxylpropyl- $\beta$ $\mathrm{CD}(\mathrm{HP}-\beta-\mathrm{CD})$ and a sugar mixture. The device with SBE- $\beta$-CD showed a significant faster rate of release hence it was concluded that SBE- $\beta$-CD provides novel properties for the development of controlled porosity osmotic pump tablets (OPT) for poorly water soluble drugs $^{[41]}$. Sotthivirat et al. ${ }^{[42]}$ prepared controlled porosity osmotic pump pellets using SBE- $\beta-C D$ as a solubilizer and an osmotic agent in combination with prednisolone, a sparingly water soluble drug. From this study it was concluded that a controlled release pattern could be achieved by modifying the molar ratio of prednisolone and SBE- $\beta-C D$.

It was observed that with a change in osmotic pressure difference across the cell membrane there is a significant change in drug release rate, which implies that the osmotic pumping may be part of a mechanism of drug release from pellet formation ${ }^{[42]}$. OPT, which has a $\mathrm{pH}$-independent release profile was prepared using chlorpromazine where SBE- $\beta-C D$ was used as a solubilizer and an osmotic agent. The release rate was controlled by modifying the membrane thickness of OPT. An intermolecular complex of chitosan and SBE- $\beta-C D$ was used to formulate slow release tablet of famotidine and was reported that they were potentially useful for controlled release of the drug. It has been reported that chitosan forms nanoparticles with $\mathrm{CD}$, which are anionic in nature and can be used in various controlled drug delivery systems to improve efficiency of the administered drug ${ }^{[43]}$. Oral liquid formulation of spironolactone proposed to be administered to premature infants was prepared and the oral absorption was studied in a prospective study. Absorption was found to be significantly higher in the formulation containing SBE- $\beta$-CD leading to an increased bioavailability. Although spironolactone showed deacetylation to some extent in presence of SBE- $\beta-C D$, paediatric formulations containing SBE- $\beta$ $\mathrm{CD}$ as an excipient is considered safe for use ${ }^{[30]}$.

\section{Sublingual delivery:}

On buccal administration, bioavailability of hepatically metabolised drugs can be substantially improved as the drugs come in contact with the buccal mucosa and permeate through the mucosal tissue thereby reaching systemic circulation. The drug thus does not enter the enterohepatic circulation and avoids the first pass metabolism. Controlled release formulation of danazole was prepared using SBE- $\beta-C D$ and an increased bioavailability was achieved as a result of enhanced solubility due to formation of a stable inclusion complex ${ }^{[44]}$.

\section{Ocular delivery:}

For ocular delivery the major challenge is to achieve sustained therapeutic effect. Mahmoud et al. ${ }^{[20]}$ measured the potential of nanostructures for ocular delivery system. Chitosan nanoparticles were prepared using SBE- $\beta-C D$ as an anionic cross linker. The in vivo studies conducted showed that the mucoadhesive nanoparticles had better sustained release property and is a promising carrier for controlled drug delivery system. SBE- $\beta$-CD was incorporated in the eye drops, which showed increased tolerability of prodrug of pilocarpine, eye irritation was reduced by many folds and no effect on the ocular absorption of the prodrug ${ }^{[24]}$. Saarinen-Savolainen et al. ${ }^{[45]}$ evaluated cytotoxicity of various ophthalmic drugs, eye drop excipients and $C D$ in human corneal epithelial cell lines and concluded that SBE- $\beta-C D$ is relatively safe on corneal epithelium. Zhang et al. developed naringenin-loaded SBE- $\beta$ CD-chitosan nanoparticles for ocular administration. The results of in vivo studies in rabbits showed that naringenin bioavailability was significantly enhanced in aqueous humor in comparison to naringenin suspension $^{[46]}$. An ocular film incorporated with inclusion complex of amlodipine with SBE- $\beta-C D$ was reported to show increased ocular permeation attributed to the presence of SBE- $\beta-C D$ in the film ${ }^{[47]}$.

\section{Nasal delivery:}

Nasal drug delivery is an attractive technique utilized mainly to attain rapid absorption, which in turn leads to a higher bioavailability for the drug candidates. It is apparently non-invasive and shows activity at lesser doses and a boon for the drugs that are rapidly metabolised once taken orally. Nasal delivery system containing ondansetron hydrochloride and SBE- $\beta$ CD showed increased permeability ${ }^{[48]}$. Nasal powder formulations of thalidomide were prepared to treat nose bleeding in persons suffering from hereditary haemorrhagic telangiectasia showed an increased absorption rate due to SBE- $\beta-C D$. On topical application of the powder on the nasal mucosa the drug gets accumulated within the tissue and shows better action $^{[49]}$. Tongiani et al. ${ }^{[3]}$ formulated midazolam nasal spray. The ring openings and ionization of the ring open forms were enhanced due to solubilisation by SBE- $\beta$ - 
$\mathrm{CD}$ and also increased the absolute bioavailability of midazolam.

\section{Pulmonary delivery:}

The lungs exhibit a few characteristic features for drug delivery such as heavy blood supply, avoidance of hepatic first-pass metabolism, and low enzymatic metabolism, which facilitates the systemic therapy by the inhalable aerosol of proteins. It provides a noninvasive and alternate system for protein delivery. In a work done by Kwon et al. ${ }^{[50]}$ proteins were loaded in porous microparticle (PM). This PM was prepared by multiemulsion method using SBE- $\beta-\mathrm{CD}$ as a porogen. The study concluded that PM having sustained release characteristics may be successfully applied for longterm pulmonary administration of protein or peptide drug. Another application of SBE- $\beta-C D$ for pulmonary delivery was reported by Mohtar et al. wherein dry powder for inhalation was prepared with the aid of SBE- $\beta$-CD-fistin complex ${ }^{[51]}$.

\section{Parenteral delivery:}

In a study McIntosh et al. ${ }^{[52]}$ reported that intravenous administration of aqueous solution of etomidate using SBE- $\beta-C D$ as a solubilizing agent had a reduced side effect profile. It was shown to possible to be given subcutaneously because of a co-solvent used in the formulation. An intramuscular dosage form of ziprasidone mesylate was developed using SBE$\beta-C D$ to solubilize the drug by complexation ${ }^{[33]}$. Pharmacokinetics (PK) and pharmacodynamics (PD) of propofol in a lipid based formulation was compared to the formulation containing SBE- $\beta$-CD complexes. The results confirmed that the PK/PD of these two formulations were substantially similar when given by IV infusion ${ }^{[53]}$.

\section{Topical delivery:}

Anraku et al. prepared a gel for topical delivery using electrostatic interactions between SBE- $\beta-C D$ and deacetylated chitin nanofibers. SBE- $\beta-C D$ was able to form a stiff, non-fluid elastic gel compared to other $\mathrm{CD}^{[54]}$. The incorporation of poorly soluble drug prednisolone in the gel was increased due to solubilizing ability of SBE- $\beta-C D^{[55]}$.

\section{NEW DRUG DELIVERY INCORPORATING

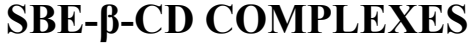

\section{Microspheres:}

Microspheres are spherical particles in the micrometer range used in drug delivery. In a study, microspheres of berberine hydrochloride and trimethoprim were prepared by ionic gelation. Initially inclusion complex of trimethoprim with SBE- $\beta-C D$ was prepared to improve solubility, stability and absorption of trimethoprim. Later berberine was included in chitosan solution followed by cross-linking chitosan solution and trimethoprim-SBE- $\beta-C D$ complex to form microspheres ${ }^{[56]}$.

\section{Liposomes:}

Liposomes have enhanced permeability and retention effects. They can be used for targeted delivery of the drugs that directly reach the site of action and show improved therapeutic activity. In a study, liposomal formulation of irinotecan was prepared by loading the drug into liposomes using SBE- $\beta-C D$, which protects the drug against hydrolysis and delivers more active drug to tumour and prolongs the exposure time. It showed that the formulation with more drug to lipid mass ratio showed high loading efficiency and was less toxic than the free irinotecan as found by acute toxicity studies $^{[57]}$.

\section{PEGylated liposomes:}

Liposomes are modified with polyethylene glycol (PEG). The hydrophobic portion of PEG is incorporated in the lipid bilayer of liposomes and it provides a stable anchor for the PEG chain. The hydrophilic head remains on the surface of the liposomes and forms a layer, which reduces the interaction between the lipid bilayer and the plasma components and hence the circulation time increases. PEGylated liposomes of vincristine were prepared where SBE- $\beta$-CD was used as a trapping agent as a result improved retention and reduced toxicity was achieved ${ }^{[58]}$.

\section{Nanoparticles:}

SBE- $\beta$-CD being polyanionic as well as a powerful solubilizer, can form nanoparticles with chitosan by ionic gelation. The size of the nanoparticles and zeta potential was influenced by chitosan/SBE- $\beta$-CD ratio. Nanoparticles were prepared using SBE- $\beta-C D$ as a polyanionic solubilizing agent and chitosan, which is a biodegradable polysaccharide for an antifungal drug (econazole nitrate) for ocular delivery. Nanoparticle formulation showed increased mucoadhesiveness and permeability. These nanoparticles were prepared using ionic gelation method. The chitosan nanoparticles could deliver the drug in efficient concentration 
to the eye hence it was considered an excellent formulation $^{[20,46,59-61]}$. Fernandes et al. reported amino acid conjugated chitosan nanoparticles for the brain delivery of saxagliptin. The nanoparticles were prepared by ionic gelation method. SBE- $\beta-C D$ was selected as the cross-linker to aid in the formation of nanoparticles ${ }^{[62]}$. SBE- $\beta$-CD-based nanoparticles were also prepared by a different procedure based on oligomers of SBE- $\beta-C D$ for moxifloxacin ${ }^{[63]}$.

\section{Nanofibers:}

Nanofibers are fibers with a diameter in the nanometer range. Electrospun nanofibers are being used to achieve various drug delivery applications. Electrospun nanofibers of sulfisoxazole-SBE- $\beta-C D$ were successfully prepared and reported to have enhanced water solubility ${ }^{[64]}$.

\section{METHODS OF PREPARATION OF INCLUSION COMPLEXES}

Various methods have been reported for the formation of SBE- $\beta$-CD-based inclusion complexes. Conventional methods such as kneading, co-precipitation, milling, spray dry technique, and freeze dry techniques are now replaced with modern methods such as hot melt extrusion (HME), and supercritical fluid techniques (Table 4) ${ }^{[65-69]}$. Supercritical fluid-based method for the production of complexes involves the use of an organic solvent and an antisolvent (carbon dioxide). The drug and SBE- $\beta-C D$ is first dissolved in the organic solvent and then this mixture is introduced into a chamber, which contains antisolvent in its super critical state with help of a nozzle. As soon as the antisolvent comes in contact with the solution, it rapidly diffuses into the organic solvent and in the same way the organic solvent counter diffuses out. As this super critical fluid has lower solvent power than the organic solvent it gets super saturated, which results in precipitation of the solute and the solvent gets carried away with the super critical fluid flow. This method is recommended for heat liable drugs. It is an efficient method for improving the bioavailability of the drugs. It is a fast process with low maintenance cost although it requires a high initial cost. The advantage of using carbon dioxide as antisolvent is that it has low critical temperature and pressure. It is non-toxic, not expensive and it can be easily removed from the materials when the process is complete. Even if a small amount remains trapped inside the polymer it is not harmful for the consumer ${ }^{[70]}$. HME is a processing technology or a specialized drug
TABLE 4: METHODS OF PREPARATION OF INCLUSION COMPLEXES OF SBE- $\beta$-CD

\begin{tabular}{lcc}
\hline Method & Drugs used & References \\
\hline Spray drying & Carbamazepine & 15 \\
Lyophilization/ & Curcumin & 16 \\
freeze drying & Furan & 17 \\
& Honokiol & 21 \\
& Erlotinib & 23 \\
& Phenytoin & 25 \\
& Nateglinide & 26 \\
& Olmesartan medoxomil & 27 \\
Kneading & Lacidipine & 28 \\
& Vinpocetine & 67 \\
& Equol & 68 \\
& 2-(2-nitrovinyl) furan & \\
& (G-0) & 66 \\
Coevaporation & Thalidomide & 19 \\
& Vinpocetine & 67 \\
Solvent & Olmesartan medoxomil & 27 \\
evaporation & Furosemide & 69 \\
Physical kneading & Silymarin & 70 \\
Hot melt & Ohalidomide & 19 \\
extrusion & Vinpocetine & 67 \\
& Silymarin & 70 \\
& Silymarin & 70 \\
& & \\
& Thalidomide & 27 \\
& Ketoprofen & 19 \\
& & \\
\hline
\end{tabular}

delivery system that does not require any solvent or any complicated processing mechanism for making matrix composites. Complexes are formed by melting thermoplastic polymers. Polymers which have glass transition temperature below the degradation temperature of the drug are used. Polyethylene oxide, hydroxypropyl cellulose and Eudragit has been widely used as thermal binders and retardants. The influence of SBE- $\beta$-CD (Captisol ${ }^{\circledR}$ ) on the dissolution properties of a poorly water-soluble drug (ketoprofen) from extrudates prepared by HME was studied and compared with the complex prepared with other methods like physical mixing, co-grinding, and freeze drying. The dissolution rate of ketoprofen complex prepared by HME was found to be significantly high. SBE- $\beta-C D$ has been reported to be hygroscopic in nature and this leads to particle aggregation and hence leads to slow drug release. But complexes prepared by extrusion method were found to be least affected when it was exposed to elevated humidity ${ }^{[71]}$.

\section{CLINICAL SAFETY}

The drug SBE- $\beta$-CD complex increases efficacy and potency leading to a reduction of dose required to attain optimum therapeutic activity through increasing drug solubility. Hence, by making the drug effective 
TABLE 5: VARIOUS MARKETED PRODUCTS BASED ON SBE- $\beta-C D$ INCLUSION COMPLEXES

\begin{tabular}{|c|c|c|c|c|}
\hline Marketed products & Brand & Drugs & Therapeutic use & Dosage form \\
\hline Noxafil & Merck & Posaconazole & Antifungal & Intravenous infusion \\
\hline Kyprolis & Amgen & Carfilzomib & Multiple myeloma & Injection \\
\hline Nexterone & Baxter & Amiodarone $\mathrm{Hcl}$ & Arrhythmia & Injection \\
\hline Cerenia & Pfizer & Maropitant citrate & For vomiting & Tablet \\
\hline VFend & Pfizer & Voriconazole & Antifungal & Intravenous injection \\
\hline Geodon,Zeldox & Pfizer & Ziprasidone maleate & $\begin{array}{l}\text { Atypical antipsychotic, } \\
\text { schizophrenia }\end{array}$ & Intramuscular injection \\
\hline Abilify & $\begin{array}{l}\text { Bristol-Mayers } \\
\text { Squibb }\end{array}$ & Aripiprazole citrate & Antipsychotic, schizophrenia & Tablet \\
\hline Evomela & $\begin{array}{c}\text { Spectrum } \\
\text { Pharmaceuticals }\end{array}$ & Melphalan & Multiple myeloma & Injection \\
\hline Carnexiv & Lundbeck & Carbamazepine & Antiepileptic & Injection \\
\hline Baxdela & Baxdela & Delafloxacin & Antibacterial & Tablet, intravenous injection \\
\hline
\end{tabular}

at lower doses it reduces the possible drug toxicity. A list of marketed formulations based on SBE- $\beta-C D$ inclusion complexes is presented in Table 5. SBE- $\beta$-CD was found to significantly decrease the eye irritation of an ophthalmically applied pilocarpine prodrug solution for miotic response. It reduces the amount of free drug concentration in the precorneal area to a non-irritating level ${ }^{[24]}$. In a study done by Nagase et al..$^{[31]}$ to evaluate the cytotoxicity of various drugs, excipients and CD in immortalized human corneal epithelial cell line, SBE- $\beta-C D$ were found to be least toxic ${ }^{[31]}$. Poorly water soluble drugs tend to have toxicities as they remain in the crystalline form when used in parenteral formulation, which can be effectively reduced by formation of complexes with SBE- $\beta$-CD. A lipid emulsion based marketed formulation of propofol is reported to have some undesirable properties such as serious allergic reactions and also supports microbial growth. Formation of a SBE- $\beta$-CD-based formulation of propofol has been found to be advantageous as there is reduction of incidences of formulation based side effects $^{[51]}$. SBE- $\beta-C D$ was found to inhibit cytotoxicity towards human umbilical vein endothelial cells by DY-9760e and also significantly suppressed the druginduced vascular damage in rabbits ${ }^{[31]}$.

In a study conducted for a parenteral preparation of voriconazole where SBE- $\beta-C D$ was used as solubilizing agent, no apparent effects were found on respiratory or cardiovascular system, autonomic and somatic nervous system ${ }^{[72]}$. At a dose of $1500 \mathrm{mg} / \mathrm{ml}$ no histopathological evidence of toxicity was found in kidney of dogs. But at dose of $3000 \mathrm{mg} / \mathrm{ml}$ (this dose of SBE- $\beta-C D$ is 50 folds higher than what is normally administered) mild toxicity in the kidney and liver was observed. Renal tubular vacuolation and foamy macrophages in the liver and lungs was noted. Studies conducted on subjects with renal dysfunction revealed that the plasma level of the accumulated SBE- $\beta-C D$ did not pose any deleterious effects on the renal function. SBE- $\beta-C D$ is primarily cleared by kidney and renal dysfunction results in accumulation of SBE- $\beta$-CD in plasma. Luke et al. studied the dialyzability of SBE- $\beta$ $\mathrm{CD}$ in patients with renal dysfunction. Haemodialysis effectively removed SBE- $\beta-C D$ from the vascular space $^{[73]}$. Hoover et al. examined the PK and safety of SBE- $\beta-C D$ by administration of intravenous infusions containing SBE- $\beta-C D$ in subjects with renal impairment. The study concluded that decreased renal function resulted in reduced SBE- $\beta-C D$ clearance. However, SBE- $\beta-C D$ exhibited good safety and tolerability profile ${ }^{[74]}$. In another study SBE- $\beta-C D$ was shown to be well-tolerated in high doses when administered intraperitoneally in mice. Histological lesions were absent in mice receiving SBE- $\beta-C D$ and did not show any significant anticoagulant activity suggesting that they were biologically safe ${ }^{[75]}$.

SBE- $\beta-C D$ is a versatile derivative of the parent $\beta$ $\mathrm{CD}$. The ability to solubilize poorly soluble drugs is higher than parent $\beta-\mathrm{CD}$ due to the presence of hydrophobic butyl moiety. SBE- $\beta-C D$ can be applied for use in formulation of various drug delivery systems incorporating a variety of guest molecules ranging from small molecules to large compounds, peptides and proteins. An optimised inclusion complex can be an efficient strategy to increase the solubility of poorly soluble compounds and provide stability to a large number of active pharmaceutical ingredients. Being able to be produced from extremely simple processes, SBE- $\beta$-CD inclusion complexes can be a viable technique to reduce the dose of the drug candidates 
and thereby possibly reducing the occurrence of drug related toxicities.

\section{Conflict of interest:}

The authors would like to declare no conflicts of interest.

\section{REFERENCES}

1. Szejtli J. Introduction and general overview of cyclodextrin chemistry. Chem Rev 1998;98(5):1743-54.

2. Li J, Xiao H, Li J, Zhong Y. Drug carrier systems based on water-soluble cationic $\beta$-cyclodextrin polymers. Int $\mathrm{J}$ Pharm 2004;278(2):329-42.

3. Tongiani S, Ozeki T, Stella VJ. Sulfobutyl ether-alkyl ether mixed cyclodextrin derivatives with enhanced inclusion ability. J Pharm Sci 2009;98(12):4769-80.

4. Zia V, Rajewski RA, Bornancini ER, Luna EA, Stella VJ. Effect of alkyl chain length and degree of substitution on the complexation of sulfoalkyl ether $\beta$-cyclodextrins with steroids. J Pharm Sci 1997;86(2):220-4.

5. Merzlikine A, Abramov YA, Kowsz SJ, Thomas VH, Mano T. Development of machine learning models of $\beta$-cyclodextrin and sulfobutylether- $\beta$-cyclodextrin complexation free energies. Int J Pharm 2011;418(2):207-16.

6. Irie $\mathrm{T}$, Uekama $\mathrm{K}$. Pharmaceutical applications of cyclodextrins. III. Toxicological issues and safety evaluation. J Pharm Sci 1997;86(2):147-62.

7. Zia V, Rajewski RA, Stella VJ. Effect of cyclodextrin charge on complexation of neutral and charged substrates: comparison of (SBE) $7 \mathrm{M}-\beta-\mathrm{CD}$ to HP- $\beta$-CD. Pharm Res 2001;18(5):667-73.

8. Chandra A, Ghate VM, Aithal $\mathrm{KS}$, Lewis $\mathrm{SA}$. In silico prediction coupled with in vitro experiments and absorption modeling to study the inclusion complex of telmisartan with modified beta-cyclodextrin. J Incl Phenom Macrocycl Chem 2018:91:47-60.

9. Connors KA. The stability of cyclodextrin complexes in solution. Chem Rev 1997;97(5):1325-58.

10. Thompson DO. Cyclodextrins-enabling excipients: their present and future use in pharmaceuticals. Crit Rev Ther Drug Carrier Syst 1997;14(1):1-104.

11. Zia V, Rajewski RA, Stella VJ. Thermodynamics of binding of neutral molecules to sulfobutyl ether $\beta$-cyclodextrins (SBE$\beta$-CDs): the effect of total degree of substitution. Pharm Res 2000;17(8):936-41.

12. de Boer T, de Zeeuw RA, de Jong GJ, Ensing K. Recent innovations in the use of charged cyclodextrins in capillary electrophoresis for chiral separations in pharmaceutical analysis. Electrophoresis 2000;21(15):3220-39.

13. Puskás I, Varga E, Tuza K, Szeman J, Fenyvesi E, Sohajda $\mathrm{T}$, et al. Cyclodextrins: Synthesis, Chemical Applications and Role in Drug Delivery. New York (NY): Nova Science Publishers; 2015. p. 293-320.

14. Ueda $\mathrm{H}, \mathrm{Ou} \mathrm{D}$, Endo $\mathrm{T}$, Nagase $\mathrm{H}$, Tomono $\mathrm{K}$, Nagai T. Evaluation of a sulfobutyl ether $\beta$-cyclodextrin as a solubilizing/stabilizing agent for several drugs. Drug Dev Ind Pharm 1998;24(9):863-7.

15. Jain AS, Date AA, Pissurlenkar RR, Coutinho EC,
Nagarsenker MS. Sulfobutyl ether7- $\beta$-cyclodextrin (SBE7 $\beta$-CD) carbamazepine complex: preparation, characterization, molecular modeling, and evaluation of in vivo anti-epileptic activity. AAPS PharmSciTech 2011;12(4):1163-75.

16. Cutrignelli A, Lopedota A, Denora N, Iacabazzi RM, Fanizza E, Laquintana V, et al. A New Complex of Curcumin with Sulfobutylether- $\beta$-Cyclodextrin: Characterization Studies and In vitro Evaluation of Cytotoxic and Antioxidant Activity on HepG-2 Cells. J Pharm Sci 2014;103(12):3932-40.

17. Ribeiro L, Carvalho RA, Ferreira DC, Veiga FJ. Multicomponent complex formation between vinpocetine, cyclodextrins, tartaric acid and water-soluble polymers monitored by NMR and solubility studies. Eur J Pharm Sci $2005 ; 24(1): 1-3$.

18. Jablan J, Weitner T, Gabricevic M, Jug M. Stability and structure of inclusion complexes of Zaleplon with natural and modified cyclodextrins. Croat Chem Acta 2011;84(2):169-78.

19. Kale R, Tayade P, Saraf M, Juvekar A. Molecular Encapsulation of Thalidomide with Sulfobutyl Ether-7 $\beta$-Cyclodextrin for Immediate Release Property: Enhanced In vivo Antitumor and Antiangiogenesis Efficacy in Mice. Drug Dev Ind Pharm 2008;34(2):149-56.

20. Mahmoud AA, El-Feky GS, Kamel R, Awad GE. Chitosan/sulfobutylether- $\beta$-cyclodextrin nanoparticles as a potential approach for ocular drug delivery. Int J Pharm 2011;413(1):229-36.

21. Xu C, Tang Y, Hu W, Tian R, Jia Y, Deng P, et al. Investigation of inclusion complex of honokiol with sulfobutyl ether- $\beta$ cyclodextrin. Carbohydr Polym 2014;113:9-15.

22. Lockwood SF, O'Malley S, Mosher GL. Improved aqueous solubility of crystalline astaxanthin (3, 3'-dihydroxy- $\beta$, $\beta$-carotene-4, 4'-dione) by Captisol ${ }^{\circledR}$ (sulfobutyl ether $\beta$ cyclodextrin). J Pharm Sci 2003;92(4):922-6.

23. Devasari N, Dora CP, Singh C, Paidi SR, Kumar V, Sobhia $\mathrm{ME}$, et al. Inclusion complex of erlotinib with sulfobutyl ether$\beta$-cyclodextrin: Preparation, characterization, in silico, in vitro and in vivo evaluation. Carbohydr Polym 2015;134:547-56.

24. Järvinen $T$, Järvinen K, Urtti A, Thompson D, Stella VJ. Sulfobutyl ether $\beta$-cyclodextrin (SBE- $\beta$-CD) in eyedrops improves the tolerability of a topically applied pilocarpine prodrug in rabbits. J Ocul Pharmacol Ther 1995;11(2):95-106.

25. Savolainen $J$, Järvinen $K$, Matilainen $L$, Jarvinen $T$. Improved dissolution and bioavailability of phenytoin by sulfobutylether- $\beta$-cyclodextrin ((SBE) $7 \mathrm{~m}-\beta-\mathrm{CD})$ and hydroxypropyl- $\beta$-cyclodextrin (HP- $\beta$-CD) complexation. Int J Pharm 1998;165(1):69-78.

26. Xu J, Zhang $\mathrm{Y}$, Li X, Zheng Y. Inclusion complex of nateglinide with sulfobutyl ether $\beta$-cyclodextrin: Preparation, characterization and water solubility. $J$ Mol Struct 2017;1141:328-34.

27. Gera S, Cheruvu S, Zakkula A, Sampathi S. Synthesis and evaluation of olmesartan medoxomil complex with SBE7 $\beta$-CD for enhanced dissolution and bioavailability. Int J Pharm Pharm Sci 2016;8(1):333-43.

28. Darekar T, Aithal KS, Shirodkar R, Kumar L, Attari Z, Lewis $\mathrm{S}$. Characterization and in vivo evaluation of lacidipine inclusion complexes with $\beta-$ cyclodextrin and its derivatives. J Incl Phenom Macrocycl Chem 2016;84:225-35.

29. Wang D, Chen G, Ren L. Preparation and Characterization of the Sulfobutylether-beta-Cyclodextrin Inclusion 
Complex of Amiodarone Hydrochloride with Enhanced Oral Bioavailability in Fasted State. AAPS PharmSciTech 2017;18:1526-35.

30. Kaukonen AM, Lennernäs H, Mannermaa JP. Water-soluble $\beta$ Cyclodextrins in Paediatric Oral Solutions of Spironolactone: Preclinical Evaluation of Spironolactone Bioavailability from Solutions of $\beta$-Cyclodextrin Derivatives in Rats. J Pharm Pharmacol 1998;50(6):611-9.

31. Nagase $Y$, Hirata M, Wada $K$, Arima H, Hirayama F, Irie T, et al. Improvement of some pharmaceutical properties of DY-9760e by sulfobutyl ether $\beta$-cyclodextrin. Int $\mathrm{J}$ Pharm 2001;229(1):163-72.

32. Jain AC, Adeyeye MC. Hygroscopicity, phase solubility and dissolution of various substituted sulfobutylether $\beta$-cyclodextrins (SBE) and danazol-SBE inclusion complexes. Int J Pharm 2001;212(2):177-86.

33. Kim Y, Oksanen DA, Massefski Jr W, Blake JF, Duffy EM, Chrunyk B. Inclusion complexation of ziprasidone mesylate with $\beta$-cyclodextrin sulfobutyl ether. J Pharm Sci 1998;87(12):1560-7.

34. Ma DQ, Rajewski RA, Vander Velde D, Stella VJ. Comparative Effects of (SBE) $7 \mathrm{~m}-\beta-\mathrm{CD}$ and HP- $\beta-\mathrm{CD}$ on the Stability of Two Anti-neoplastic Agents, Melphalan and Carmustine. J Pharm Sci 2000;89(2):275-87.

35. Loftsson $\mathrm{T}$, Guðmundsdóttir $\mathrm{H}$, Sigurjonsdottir JF, Sigurdsson HH, Sigfusson SD, Masson M, et al. Cyclodextrin solubilization of benzodiazepines: formulation of midazolam nasal spray. Int J Pharm 2001;212(1):29-40.

36. Kfoury M, Pipkin JD, Antle V, Fourmentin S. Captisol ${ }^{\circledR}$ : an efficient carrier and solubilizing agent for essential oils and their components. Flavour Fragr J 2017;32(5):340-6.

37. Shityakov S, Puskás I, Pápai K, Salvador E, Roewer N, Forster C, et al. Sevoflurane-sulfobutylether- $\beta$-cyclodextrin complex: preparation, characterization, cellular toxicity, molecular modelling and blood-brain barrier transport studies. Molecules 2015;20(6):10264-79.

38. Wang M, Jiang J, Cai Y, Zhao M, Wu Q, Cui Y, et al. In vitro and in vivo evaluation of a posaconazole-sulfobutyl ether$\beta$-cyclodextrin inclusion complex. Biomed Chromatogr 2018;32(12):e4364.

39. Järvinen K, Järvinen T, Thompson DO, Stella VJ. The effect of a modified $\beta$-cyclodextrin, SBE4- $\beta-C D$, on the aqueous stability and ocular absorption of pilocarpine. Curr Eye Res 1994;13(12):897-905.

40. Rao VM, Haslam JL, Stella VJ. Controlled and complete release of a model poorly water-soluble drug, prednisolone, from hydroxypropyl methylcellulose matrix tablets using (SBE) $7 \mathrm{~m}-\beta$-cyclodextrin as a solubilizing agent. J Pharm Sci 2001;90(7):807-16.

41. Okimoto K, Rajewski RA, Stella VJ. Release of testosterone from an osmotic pump tablet utilizing (SBE) $7 \mathrm{~m}-\beta-$ cyclodextrin as both a solubilizing and an osmotic pump agent. J Control Release 1999;58(1):29-38.

42. Sotthivirat S, Haslam JL, Stella VJ. Controlled porosityosmotic pump pellets of a poorly water-soluble drug using sulfobutylether- $\beta$-cyclodextrin, (SBE) $7 \mathrm{M}-\beta-\mathrm{CD}$, as a solubilizing and osmotic agent. J Pharm Sci 2007;96(9):2364-74.

43. Anraku M, Hiraga A, Iohara D, Pipkin JD, Uekama K, Hirayama F. Slow-release of famotidine from tablets consisting of chitosan/sulfobutyl ether $\beta$-cyclodextrin composites. Int J Pharm 2015;487(1):142-7.

44. Jain AC, Aungst BJ, Adeyeye MC. Development and in vivo evaluation of buccal tablets prepared using danazolsulfobutylether $7 \beta$-cyclodextrin (SBE 7) complexes. J Pharm Sci 2002;91(7):1659-68.

45. Saarinen-Savolainen $\mathrm{P}$, Järvinen $\mathrm{T}$, Araki-Sasaki K, Watanabe H, Urtti A. Evaluation of cytotoxicity of various ophthalmic drugs, eye drop excipients and cyclodextrins in an immortalized human corneal epithelial cell line. Pharm Res 1998;15(8):1275-80.

46. Zhang P, Liu X, Hu W, Bai Y, Zhang L. Preparation and evaluation of naringenin loaded sulfobutyl ether beta cyclodextrin chitosan nanoparticles for ocular delivery. Carbohydr Polym 2016;149:224-30.

47. Nanda A, Sahoo RN, Pramanik A, Mohapatra R, Pradhan SK, Thirumurugan A, et al. Drug-in-mucoadhesive type film for ocular anti-inflammatory potential of amlodipine: Effect of sulphobutyl-ether-beta-cyclodextrin on permeation and molecular docking characterization. Colloids Surf B Biointerfaces 2018;172:555-64.

48. Cho E, Gwak H, Chun I. Formulation and evaluation of ondansetron nasal delivery systems. Int $\mathrm{J}$ Pharm 2008;349(1):101-7.

49. Colombo G, Bortolotti F, Chiapponi V, Buttini F, Sonvico F, Invernizzi R, et al. Nasal powders of thalidomide for local treatment of nose bleeding in persons affected by hereditary hemorrhagic telangiectasia. Int J Pharm 2016;514(1):229-37.

50. Kwon MJ, Bae JH, Kim JJ, Na K, Lee ES. Long acting porous microparticle for pulmonary protein delivery. Int $\mathrm{J}$ Pharm 2007;333(1):5-9.

51. Mohtar N, Taylor KMG, Sheikh K, Somavarapu S. Design and development of dry powder sulfobutylether- $\beta$-cyclodextrin complex for pulmonary delivery of fisetin. Eur J Pharm Biopharm_2017;113:1-10.

52. McIntosh MP, Schwarting N, Rajewski RA. In vitro and in vivo evaluation of a sulfobutyl ether $\beta$-cyclodextrin enabled etomidate formulation. J Pharm Sci 2004;93(10):2585-94.

53. EganTD, Kern SE, JohnsonKB, Pace NL. The pharmacokinetics and pharmacodynamics of propofol in a modified cyclodextrin formulation (Captisol ${ }^{\circledR}$ ) versus propofol in a lipid formulation (Diprivan $\left.{ }^{\circledR}\right)$ : an electroencephalographic and hemodynamic study in a porcine model. Anesth Analg 2003;97(1):72-9.

54. Anraku M, Iohara D, Higara A, Uekama K, Ifuku S, Pipkin JD, et al. Formation of elastic gels from deacetylated chitin nanofibers reinforced with sulfobutyl ether beta-cyclodextrin. Chem Lett 2015;44:285-7.

55. Tabuchi R, Azuma K, Izumi R, Tanou T, Okamoto Y, Nagae T, et al. Biomaterials based on freeze dried surface-deacetylated chitin nanofibers reinforced with sulfobutyl ether betacyclodextrin gel in wound dressing applications. Int J Pharm 2016;511:1080-7.

56. Tong Q-P, Sun H-S, Wang J-H, Wang Y, Peng Y, Jiang M, et al. Preparation and characterization of Berberine Hydrochloride and Trimethoprim Chitosan/ SBE- $\beta$-CD microspheres. J Drug Deliv Sci Technol 2018;48:300-10.

57. Li C, Cui J, Wang C, LiY, Zhang L, Xiu X, et al. Novel sulfobutyl ether cyclodextrin gradient leads to highly active liposomal irinotecan formulation. J Pharm Pharmacol 2011;63(6):765-73.

58. Cui J, Li C, Wang C, Li Y, Zhang L, Zhang L, et al. Development of PEGylated liposomal vincristine using novel sulfobutyl ether cyclodextrin gradient: Is improved drug retention sufficient to surpass DSPE-PEG-induced drug leakage. J Pharm Sci 2011;100(7):2835-48. 
59. Okimoto K, Ohike A, Ibuki R, Aoki O, Ohnishi N, Irie T, et al. Design and evaluation of an osmotic pump tablet (OPT) for chlorpromazine using (SBE) $7 \mathrm{~m}-\beta-\mathrm{CD}$. Pharm Res 1999;16(4):549-54.

60. Fulop Z, Saokham P, Loftsson T. Sulfobutylether-betacyclodextrin/chitosan nano- and microparticles and their physicochemical characteristics. Int J Pharm 2014;472:282-87.

61. Wang $\mathrm{Z}$, Li Y. Raloxifene/SBE- $\beta-\mathrm{CD}$ Inclusion Complexes Formulated into Nanoparticles with Chitosan to Overcome the Absorption Barrier for Bioavailability Enhancement. Pharmaceutics 2018;10(3):76.

62. Fernandes J, Ghate MV, Basu MS, Lewis SA. Amino acid conjugated chitosan nanoparticles for the brain targeting of a model dipeptidyl peptidase- 4 inhibitor. Int $\mathrm{J}$ Pharm 2018;547(1-2):563-71.

63. Skuredina AA, Le-Deygen IM, Kudryashova EV. The Effect of Molecular Architecture of Sulfobutyl Ether $\beta$-Cyclodextrin Nanoparticles on Physicochemical Properties of Complexes with Moxifloxacin. Colloid J 2018;80(3):312-9.

64. Yildiz ZI, Celebioglu A, Uyar T. Polymer-free electrospun nanofibers from sulfobutyl ether-beta-cyclodextrin (SBE- $\beta$ CD) inclusion complex with sulfisoxazole: Fast-dissolving and enhanced water-solubility of sulfisoxazole. Int J Pharm 2017;531(2):550-8.

65. Ruz V, Froeyen M, Busson R, Gonzalez MM, Baudemprez L, Van den Mooter G. Characterization and molecular modeling of the inclusion complexes of 2-(2-nitrovinyl) furan (G-0) with cyclodextrines. Int J Pharm 2012;439(1):275-85.

66. Ribeiro L, Loftsson T, Ferreira D, Veiga F. Investigation and physicochemical characterization of vinpocetine-sulfobutyl ether $\beta$-cyclodextrin binary and ternary complexes. Chem Pharm Bull 2003;51(8):914-22.
67. Maeda H, Obata S, Nakayama H. Preparation and characterization of the inclusion complexes of equol with sulfobutylether- $\beta$-cyclodextrin: their antioxidant activity and dissolution evaluation. J Incl Phenom Macrocycl Chem 2018;91(3-4):125-31.

68. Spamer E, Müller DG, Wessels PL, Venter JP. Characterization of the complexes of furosemide with 2-hydroxypropyl- $\beta$ cyclodextrin and sulfobutyl ether-7- $\beta$-cyclodextrin. Eur J Pharm Sci 2002;16(4):247-53.

69. Ghosh A, Biswas S, Ghosh T. Preparation and evaluation of silymarin $\beta$-cyclodextrin molecular inclusion complexes. J Young Pharm 2011;3(3):205-10.

70. Mosher GL, Thompson DO, inventor; Cydex Inc., assignee. Formulations containing propofol and a sulfoalkyl ether cyclodextrin. Canada patent CA2441744C. 2011 Jul 12.

71. Fukuda M, Miller DA, Peppas NA, McGinity JW. Influence of sulfobutyl ether $\beta$-cyclodextrin (Captisol $\AA$ ) on the dissolution properties of a poorly soluble drug from extrudates prepared by hot-melt extrusion. Int J Pharm 2008;350(1):188-96.

72. Luke DR, Tomaszewski K, Damle B, Schlamm HT. Review of the basic and clinical pharmacology of sulfobutylether- $\beta$ cyclodextrin (SBECD). J Pharm Sci 2010;99(8):3291-301.

73. Luke D, Wood N, Tomaszewski K, Damle B. Pharmacokinetics of sulfobutylether-B -cyclodextrin (SBECD) in subjects on hemodialysis. Nephrol Dial Transplant 2012;27:1207-12.

74. Hoover RK, Alcorn H Jr, Lawrence L, Paulson SK, Quintas M, Luke DR, et al. Clinical Pharmacokinetics of Sulfobutylether$\beta$-cyclodextrin in patients with varying degrees of renal impairment. J Clin Pharmacol 2018;58(6):814-22.

75. Rajewski RA, Traiger G, Bresnahan J, Jaberaboansari P, Stella VJ, Thompson DO. Preliminary safety evaluation ofparenterally administered sulfoalkyl ether b-cyclodextrin derivatives. J Pharm Sci 1995;84:927-32. 